Canadian Studies in Population, Vol. 33.1, 2006, pp. 49-67

\title{
Familial Orientations and the Rationales for Childbearing Behaviour
}

\author{
Amir Erfani \\ Roderic Beaujot \\ Population Studies Centre \\ University of Western Ontario \\ London, Ontario, Canada
}

\begin{abstract}
Using a local qualitative sample from Ontario, we explore the rationales for childbearing behaviour across contrasting familial orientations. There are considerable similarities among respondents with traditional and modern familial orientations in terms of the reasons for having children and the costs and values of children. Nonetheless, persons with modern orientations are more likely to give individual related reasons for having children, and to see the value of children in terms of personal needs and desires. The largest difference relates to the ideal timing of childbearing, as persons with modern orientations are more likely to prefer childbearing in the late 20 s or early 30 s. While the rationales offered by respondents indicate a culture that is supportive of childbearing, and individuals with more modern orientations have views similar to those with traditional orientations on ideal family size and on the value and cost of children, they will probably have fewer children given their more individualistic orientation to childbearing and the conviction that later childbearing is better.
\end{abstract}

Key Words: Orientation to family, rationales for childbearing, value of childbearing, cost of childbearing, timing of parenthood, ideal number of children 
Amir Erfani and Roderic Beaujot

\section{Résumé}

En nous servant d'un échantillonnage qualitatif local provenant de l'Ontario, nous explorons les raisons derrières les comportements procréatifs dans des foyers d'orientations familiales différentes. Il existe d'importantes similarités entre les répondants d'orientation familiale traditionnelle et ceux d'orientation familiale moderne quant aux raison d'avoir des enfants et au sujet de la valeur accordée aux enfants et des frais qu'ils entraînent. Cependant, les personnes aux orientations modernes ont une plus forte tendance à citer des raisons personnelles pour avoir des enfants et la valeur qu'ils leurs accordent est citée comme un besoin et un désir personnel. La plus grande différence se trouve au niveau du choix du moment idéal pour la procréation, avec une tendance parmi les personnes d'orientation familiale moderne de préférer avoir des enfants vers la fin de la vingtaine ou au début de la trentaine. Les raisons offertes par les deux classes de répondants indiquent l'existence d'une culture qui soutien la procréation mais les gens d'orientation familiale plus moderne auront probablement moins d'enfants que ceux d'orientation plus traditionnelle quand on considère leur attitude plus individuelle envers la procréation et leur conviction que d'avoir des enfants plus tard dans la vie est une meilleure chose, et malgré le fait qu'ils partagent des opinions similaires avec eux au sujet du nombre idéal d'enfants et des coûts et valeurs liés aux enfants.

Mots-clés: L'orientation des familles, les raisons de la procréation, les valeurs de la procréation, le choix du moment idéal pour devenir parent, le nombre idéal d'enfants

\section{Introduction}

As a family-related behaviour, childbearing is modified by change in the values and norms associated with families. Recent demographic research has documented a drastic change in the underlying values and norms associated with family behaviour, including union formation, union dissolution, and childbearing (Lesthaeghe and Meekers 1986; Lesthaeghe and Surkyn 1988; Lesthaeghe, 1995; Surkyn and Lesthaeghe, 2002; Lapierre-Adamcyk and Lussier, 2003). The substantial shift from traditional to modern familial values signifies a "reorientation of ideals" in recent decades (Lesthaeghe and Meekers 1986; Lesthaeghe and Surkyn 1988). Traditional familial values, which are reflected in familism, emphasize commitment to the family as a unit and consider the "heterosexual nuclear family" as the only legitimate form of union. In contrast, modern familial values, which are rooted in individualism, place less value on marriage and the family unit, and take a pluralist orientation to alternate forms of family behaviour (e.g., cohabitation, single parent family, same-sex unions, divorce). 
Several demographers and sociologists have explored the shifts in familial values that have been observed in Western developed societies, along with the links to childbearing. For instance, in their article on "Family diversity and change in Britain and Western Europe" Allan and his colleagues (2001: 820) speak of a change from "family cycle," where people "married, had and raised children, and then lived as a couple until one spouse died," to "family life" as an "age of diversity in family-related issues." The "heterosexual nuclear family" includes the ideas of marriage of one man and one woman, along with families that include parents and children, and the complementary roles of men and women in unions. In contrast, "family life" is based on the values of individualism, where various alternatives are legitimated in terms of the interests of self-fulfillment.

In effect, individualism can be seen as the base for pluralist views on alternate forms of family behaviour, as individuals give priority to their "well-being and self-expression" (Van de Kaa 1987, 2001: 294). Thornton (2001) proposes that individualism is the basis of family change in industrialized countries and around the world, as people choose their own partners, and partners choose their desired form of relationship. Similarly, Roussel (1989) speaks of a change from conformity to an institution, to a "projet de couple" where people define their own relationships. In her interpretation of gender change over the previous century, Folbre (2000) proposes that these changes have allowed women to make family and childbearing decisions based on their self-interests.

In his interpretation of change Kettle (1980) contrasts a "dutiful generation" and a "me generation". Dutiful generations put duty prior to pleasure, value the institution of marriage, sacrifice for others, and children in particular, and are oriented toward children. In contrast, Me generations are not as ready to sacrifice everything for their children. If there is a conflict of interest, the person from the dutiful generation would make self-sacrifice for the benefit of other family members, while the me generation would first think of their own interests.

Similarly, Giddens $(1991,1992)$ sees a "transformation of intimacy" into "pure relationships" which exist solely on the basis of the individuals wanting the relationships. Pure relationships are reflexive in the sense that there is continuous appraisal of the value of the relationship for the individual. In effect, Giddens (1992: 90-94) contrasts two forms of relationships: addictive and pure. In the "addictive" type, the relationship is secured through complementarity based on recognized roles and duties. In contrast, an individual enters a pure relationship solely for the purpose of this relationship, not for ulterior motives such as forming a family or having children. In addition, in a pure relationship the individual faces a pluralism of possible life styles, and selects through a 
process of negotiation. In the case of childbearing, for example, one possibility is to have children, as a form of gratification. However, there are risks associated with having children and childbearing is often delayed as other gratifications are achieved.

The researchers who have examined the relationship between familial orientations and reproductive behaviour propose that modern familial orientations are linked with delayed childbearing and low fertility. For instance, Moors (1996) investigated the impacts of value orientations on the transition to parenthood, using longitudinal panel data. He found that women who identified with modern family values had a significant lower risk of having a first birth or getting pregnant than those women who valued traditional family values. Hall (2003) studied the relationship between pure relationship and fertility intentions. He found that couples who conformed to the values of pure relationships were more likely to have lower fertility intentions. Others have documented a stable association between demographic outcomes and values orientations (Lesthaeghe and Moors, 2000).

Our purpose is to further elaborate the links between these orientations to family and the rationales for childbearing. In particular, we expect to find differences in the rationales given for childbearing behaviour, depending on the orientation toward family. Individuals, who are oriented towards traditional familial values and norms, are expected to offer rationales for childbearing behaviour that are more child-centered, rather than union or self-centered. For instance, those who see the only possible type of family as involving one man and one woman, along with children, would be more likely to be pro-children and to consider subordinating their interests to those of children and family. In contrast, those who are more tolerant toward same-sex unions, lone parent families, cohabiting unions and children in cohabiting unions, would have a modern familial orientation, they would be less pro-children, and their personal interests would be given greater priority over children's interests. The rationales for childbearing behaviour include not only the reasons for having children but also the values and costs of having children, and the timing of the transition to parenthood. We consider the similarities and differences in these rationales offered for having children, between persons who are traditional and those who are modern in their familial orientations. While there are various other possible means of highlighting family diversity, and many dimensions of families, this paper pays particular attention to these modern vs. traditional familial orientations and their relationship to rationales for childbearing behaviour. 


\section{Data and Method}

The data used here are taken from a 2000 survey of orientations to marriage, relationships and childbearing that was conducted in London, Ontario, and the surrounding region. This sample included all persons over 18 years of age in the selected households, based on census enumeration areas which had been stratified by income level as well as location (city, town, rural areas). The household response rate was 48.3 percent, and in these households 76.6 percent of eligible respondents completed the survey. The 1071 respondents included 124 who underwent a semi-directed interview. This study is based on this subsample which contains 74 women and 50 men aged 18 to 82 years. Given the response rate, we cannot claim to have a representative sample. However, our purpose is to explore the alternate rationales for childbearing behaviours and to relate these to familial orientations.

In the section on childbearing, interviews sought to determine the prevalent rationales for childbearing behaviour through asking about reasons, values, costs, and timing of having children as well as ideal number of children. We wanted to know what people use as the legitimate reasons in making decisions about having children. Thus, respondents were asked: "What do you see as the disadvantages of having children? What is the best age for women to have their first child? What do you think is the ideal number of children most people should have?" "Why do you think people usually decide to have children?" In effect, respondents were also treated as informants on the predominant culture. We assume that the answers to these questions, or the reasons given for their own behaviour, can help understand the rationales the respondents see as legitimate for justifying their reproductive behaviours.

Respondents were first divided into alternative familial orientations on the basis of four attitudinal items. These four items were selected from a series of items by varimax rotation. The selected items reflected the orientation toward having children in the context of cohabitation, single parent, same sex, and two parent unions: (1) When two people decide to have children they should first get married. (2) A single woman should never choose to have a child. (3) A same sex couple should have the right to have a child. (4) A child needs a home with both a father and a mother to grow up happily. Four choices were provided for each item in the format of the Likert scale -- strongly agree, agree, disagree, and strongly disagree. The items were coded in the same direction and summed over the four questions to develop a composite index of familial orientation. The index had an acceptable reliability (alpha $=.74$ ) which was able to explain 56.3 per cent of variation in the concept of familial orientation (see Table 1). Those who had scores ranging from 4 to 9 were classified as respondents with a modern familial orientation (29\%), and those with scores from 13 to 16 were 
classified as traditional (31.8\%). The rest of respondents $(38.3 \%)$ were placed in a middle category labeled intermediate. We mostly contrast the rationales of traditional and modern respondents. While the focus is on the qualitative responses, Table 2 presents some descriptive statistics on the respondents, according to their familial orientation. People with traditional orientation are more likely to be in marital unions, older, higher socio-economic status, and to have more children. In contrast, modern respondents are younger, more likely to be single or in cohabiting unions, with lower socioeconomic status, and fewer children.

\section{Rationales for Childbearing Behaviour}

The rationales for childbearing behaviour are now differentiated according to these three familial orientations. The results are quantified in Table 3, with examples of the various attitudes quoted below according to the four dimensions under investigation: reasons for having children, values and costs of children, timing of parenthood, and ideal number of children.

\section{Reasons for Having Children}

In response to question on why people usually decide to have children, as we expected, most of traditional respondents (75\%) gave family related reasons for having children:

I think in general the first idea is to complete a family. A husband and wife aren't a family, it's always a husband and wife and children [3130, man, age 35, married, 3 kids, SES high].

You want to have children, you feel that something is missing in your lives. [18160, man, age 47, married, 2 kids, SES high].

I think one reason is that you want to have children because the family is not complete without children. Why would you get married if you don't want to have children? Besides I think it is really nice if you have your own family. You can plan something for the future. [12661, woman, age 54, married, 3 kids, SES high]. 
Familial Orientations and the Rationales

for Childbearing Behaviour

Table 1

Percentage Distribution of Respondents by the Indicators of Familial Orientations, London and Surrounding Areas, 2000

\begin{tabular}{|c|c|c|c|c|c|}
\hline Indictor & $\begin{array}{l}\text { Strongly } \\
\text { Agree }\end{array}$ & Agree & Disagree & $\begin{array}{l}\text { Strongly } \\
\text { Disagree }\end{array}$ & Total \\
\hline $\begin{array}{l}\text { 1. When two people decide to } \\
\text { have children they should first } \\
\text { get married }\end{array}$ & 43.9 & 38.3 & 15 & 2.8 & 100 \\
\hline $\begin{array}{l}\text { 2. A single woman should } \\
\text { never choose to have a child }\end{array}$ & 13.1 & 19.6 & 45.8 & 21.5 & 100 \\
\hline $\begin{array}{l}\text { 3. A same sex couple should } \\
\text { have the right to have a child }\end{array}$ & 9.3 & 26.2 & 38.3 & 26.2 & 100 \\
\hline $\begin{array}{l}\text { 4. A child needs a home with } \\
\text { both a father and a mother to } \\
\text { grow up happily }\end{array}$ & 16.8 & 39.3 & 34.6 & 9.3 & 100 \\
\hline
\end{tabular}

$\mathrm{N}=107$

Descriptive Statistics of the index of familial orientation:

Minimum value: $4.0 \quad$ Mean: 10.9 Mode: 10.0 Median: 11.0

Maximum Value: $16 \quad S E: .26 \quad S D: 2.66$

Cronbach's Alpha $=.74$

Percent of explained variance by above four Indicators $=56.3$ 
Amir Erfani and Roderic Beaujot

Table 2

Familial Orientations by Socio-demographic Variables for London and Surrounding Areas, 2000

\begin{tabular}{|c|c|c|c|c|}
\hline Variable & Modern & Intermediate & Traditional & Sample Size \\
\hline \multicolumn{5}{|l|}{ Gender $^{\dagger}$} \\
\hline Male & 22.7 & 36.4 & 40.9 & 44 \\
\hline Female & 34.9 & 39.7 & 25.4 & 63 \\
\hline \multicolumn{5}{|l|}{ Birth Cohort ${ }^{* * * *}$} \\
\hline 1940 and under & 0 & 41.4 & 58.6 & 29 \\
\hline 1941-1960 & 22.7 & 43.2 & 34.1 & 44 \\
\hline 1961-1982 & 67.8 & 29 & 3.2 & 31 \\
\hline \multicolumn{5}{|l|}{ Highest Level of Education ${ }^{\dagger}$} \\
\hline $\begin{array}{l}\text { Some high school/ High } \\
\text { school graduation }\end{array}$ & 24.2 & 37.9 & 37.9 & 29 \\
\hline Technical Training/ Some & 27 & 32.4 & 40.6 & 37 \\
\hline \multicolumn{5}{|l|}{ College/ College } \\
\hline Some University/ University & 48 & 32 & 20 & 25 \\
\hline \multicolumn{5}{|l|}{ Degree } \\
\hline Professional or Graduate & 20 & 70 & 10 & 10 \\
\hline \multicolumn{5}{|l|}{ Degree } \\
\hline Others & 20 & 60 & 20 & 5 \\
\hline \multicolumn{5}{|l|}{ Marital Status $^{* * * *}$} \\
\hline Married & 14.1 & 40.6 & 45.3 & 64 \\
\hline Single & 70.6 & 23.5 & 5.9 & 17 \\
\hline Separated/Divorced/Widowed & 37.5 & 43.8 & 18.7 & 16 \\
\hline Cohabited & 50 & 40 & 10 & 10 \\
\hline \multicolumn{5}{|l|}{ Work Status ${ }^{\ddagger}$} \\
\hline Full Time & 26.7 & 42.2 & 31.1 & 45 \\
\hline Non Paid & 28.6 & 35.7 & 35.7 & 28 \\
\hline Part Time & 22.2 & 33.3 & 44.5 & 18 \\
\hline Student & 61.5 & 38.5 & 0 & 13 \\
\hline \multicolumn{5}{|l|}{ Socioeconomic Status ${ }^{*}$} \\
\hline High & 14.7 & 41.2 & 44.1 & 34 \\
\hline Medium & 26.2 & 47.6 & 26.2 & 42 \\
\hline Low & 50 & 22.2 & 27.8 & 18 \\
\hline \multicolumn{5}{|l|}{ Type of Household ${ }^{* * *}$} \\
\hline Couple with children home & 22.2 & 38.9 & 38.9 & 36 \\
\hline Couple with children away & 4.2 & 41.7 & 54.2 & 24 \\
\hline Single & 66.7 & 20 & 13.3 & 15 \\
\hline Couple with no children & 30 & 40 & 30 & 10 \\
\hline Othere ${ }^{1}$ & 47.6 & 42.9 & 9.5 & 21 \\
\hline \multicolumn{5}{|l|}{ Number of Children ${ }^{* * * *}$} \\
\hline 0 & 68 & 24 & 8 & 25 \\
\hline 1 & 37.5 & 50 & 12.5 & 8 \\
\hline 2 & 22.6 & 48.4 & 29 & 31 \\
\hline 3 & 15.4 & 34.6 & 50 & 26 \\
\hline $4+$ & 6.2 & 37.5 & 56.3 & 16 \\
\hline
\end{tabular}

$* * * \mathrm{P} \leq .001, * \mathrm{P} \leq .05, \ddagger \mathrm{P} \leq .10, \dagger \mathrm{P} \leq .20 \quad$ (Significant level of Chi-squared test)

${ }^{1}$ Composed of "Single Parent (6), Blended Family (3), Step Parent (2), and Others (10) “ 
About half of respondents with modern orientation also gave family related reasons for having children, but they were also likely to give individual related reasons, as illustrated in the following quotes:

Just the joy of being around children. I think they keep people young. I think they are there when you're old. A lot of people think of it in that respect. I think a lot of people think you know, I don't want to be old and alone. I don't want to be 60 years old and not have children or grandchildren, so a lot of people do it for that reason. [6122, man, age 27, cohabited, no kid, SES low].

[...] They make you feel good to look at, to touch, to play with, to talk to. [...] They give you a sense of purpose and responsibility that seems to put other things in your life in perspective. Without them, you might take things a little more seriously, but with them you tend to realize that this problem isn't such a big problem. I'm just in more of a better, positive state of mind, the days are better, I have more energy, I feel better when I'm with kids. [11482, male, age 30, single, no kids, SES high].

\section{Values of having children}

When the respondents were asked about the advantages of having children, over half of respondents spoke about psychological values of having children. They believe that children bring "love, joy, happiness, and satisfaction" into life as well as the "companionship" which help parents to get rid of "loneliness" and a "boring life" thorough sharing their "loves, values, times, teachings, and entertainments" with children. These psychological values of having children were more often given by modern respondents.

I think it's just another person to love and to watch grow.[5131, woman, age 25, married, no kid, SES low].

I think they bring a lot of pleasure to your life, a lot of joy. [6583, woman, age 49, single, no kid, SES medium].

I think life is just so much better with kids, someone to share your life with, it's a part of you. Having a child is just such a 
Amir Erfani and Roderic Beaujot

Table 3

Profile of Rationales for having Children by Familial Orientations

for London and Surrounding Areas: 2000

\begin{tabular}{|c|c|c|c|c|}
\hline Rationales for Having Children & Modern & $\begin{array}{c}\text { Inter- } \\
\text { mediate }\end{array}$ & Traditional & Total \\
\hline \multicolumn{5}{|l|}{ The reasons for childbearing* } \\
\hline Individual-related reasons & $51.9(14)$ & $47.2(17)$ & $25.0(8)$ & $41.0(39)$ \\
\hline Family-related reasons & $48.1(13)$ & $52.8(19)$ & $75.0(24)$ & $59.0(56)$ \\
\hline \multicolumn{5}{|l|}{ Values of having children } \\
\hline Psychological values & $76.0(19)$ & $47.1(16)$ & $48.4(15)$ & $55.6(50)$ \\
\hline Socio-cultural values & $24.0(6)$ & $52.9(18)$ & $51.6(16)$ & $44.4(40)$ \\
\hline \multicolumn{5}{|l|}{ Cost of having children } \\
\hline No costs & $25.9(7)$ & $27.3(9)$ & $44.8(13)$ & $32.6(29)$ \\
\hline Economic costs & $25.9(7)$ & $24.2(8)$ & $13.8(4)$ & $21.3(19)$ \\
\hline Time consuming & $22.2(6)$ & $27.3(9)$ & $27.6(8)$ & $25.8(23)$ \\
\hline Psychological costs (Being worry) & $14.8(4)$ & $12.1(4)$ & $10.3(3)$ & $12.4(11)$ \\
\hline Costs come from parents & $11.1(3)$ & $9.1(3)$ & $3.4(1)$ & $7.9 \quad(7)$ \\
\hline \multicolumn{5}{|l|}{ Timing of parenthood ${ }^{* * *}$} \\
\hline Early-twenties (18-24) & $4.0(1)$ & $16.0(6)$ & $22.6(7)$ & $15.0(14)$ \\
\hline Late-twenties (25-29) & $32.0(8)$ & $43.3(16)$ & $25.8(8)$ & $34.4(32)$ \\
\hline Early-thirties $(30-35)$ & $32.0(8)$ & $10.8(4)$ & $0.0(0)$ & $12.9(12)$ \\
\hline Conditional time $^{1}$ & $24.0(6)$ & $16.0(6)$ & $51.6(16)$ & $30.1(28)$ \\
\hline Soon after marriage & $4.0(1)$ & $2.7(1)$ & $0.0(0)$ & $2.2(2)$ \\
\hline A few years after marriage & $4.0(1)$ & $16.0(4)$ & $0.0(0)$ & $5.4(5)$ \\
\hline \multicolumn{5}{|l|}{ Ideal number of children } \\
\hline 2 & $47.8(11)$ & $48.6(18)$ & $27.6(8)$ & $41.6(37)$ \\
\hline 3 & $13.0(3)$ & $13.5(5)$ & $10.3(3)$ & $12.4(11)$ \\
\hline 2 to $4^{2}$ & $17.4(4)$ & $13.5(5)$ & $34.5(10)$ & $21.3(19)$ \\
\hline Depend on parents' situations & $21.7(5)$ & $24.3(9)$ & $27.6(8)$ & $24.7(22)$ \\
\hline
\end{tabular}

$* * * \mathrm{P} \leq .001, * * \mathrm{P} \leq .01, * \mathrm{P} \leq .05$ (Significant level of Chi-squared test).

${ }^{1}$ Composed of "when financial, housing and education are set up; it varies couple to couple; when parents are mature, have stable relationship, and emotionally ready to accept the responsibility of child".

2 This includes five cases indicating four or more children as the ideal.

Note: Results were computed by using respondents' first answers to each question;

most of respondents stated only one answer to each question; numbers in table are percentage (frequency). 
miracle. [10453, woman, age 30, separated, 2 kids, SES medium].

They fulfil your life. They fill out your life basically. [13151, woman, age 40, married, 2 kids, SES low].

They're such fun. Geez. They're a lot of fun. They make you look at yourself a lot. Often they relieve you of doing something you don't even want to do [21420, man, age 25, married, no kid, SES low].

In contrast, over half of traditional respondents gave social and cultural values for having children. They offer rationales that relate to the familial and societal functions of childbearing. They believe that children carry on the family line, provide support to aging parents, and contribute to the future of their society.

They can look after you when you are old [10192, man, age 55, single, no kid, SES low].

There will be at least one there to see what you need. Not to take care of you, but there is someone there that when you grow old you can call and say I need this or can you get this for me. [12661, woman, age 59, married, 3 kids, SES high].

Also it carries on the family, you are adding to the world. [...] Without children society would die. [23452, man, age 18, single, no kid, SES medium].

They're our future and the future of the world. [25333, woman, age 81, widowed, 1 kid, SES high].

Without them our society would die. That is a value in and of itself. If we decided not to have children anymore, eventually our society would be gone. [23450, man, age 55, married, 3 kids, SES medium]. 


\section{Costs of Having Children}

In response to question on what are the disadvantages of having children, a third of respondents said that there are no disadvantages (Table 3). Among traditional respondents, half said that there were no real disadvantages to having children:

For everything you lose you gain. And that's a fact. And the same thing with having kids. You lose your freedom in a sense but then you gain a lot of pleasure out of the kids too. [21160, man, age 60, married, 3 kids, SES low].

The rest of respondents listed a number of economic, time and psychological costs which did not vary extensively between traditional and modern respondents. However, those with a modern orientation were the most prone to see children as an economic burden. They believe that children are "great financial loss", they are "money consuming", and a "handicap" for women's careers:

If you really want to have a career, having a child is pretty much a pox on that. It's the worst thing you could possibly do if you haven't planned really carefully. And financially it's extremely difficult. Especially if you do want to raise your child without day care or babysitters or having somebody else watch your child take their first steps. It's going to be pretty hard to manage that financially. [21421, woman, age 25, married, no kid, SES low].

Although respondents mentioned a long list of disadvantages of having children, when they were asked whether these reasons are strong enough not to have children, most said that the advantages outweighed the disadvantages. Only two respondents answered that there were more disadvantages. That is, while respondents were well aware of the costs of children, for the vast majority these did not outweigh the benefits of having children.

\section{Timing of Parenthood}

When the respondents were asked what age is the best for women to begin having children, a third said there was no one "ideal age". Half of traditional respondents gave the answer that there was no ideal age, or that it depended on specific circumstances. The other respondents suggested an ideal age or a range in ages seen as best for women to start having children. As would be expected, 
the modern respondents were less likely to favour early timing, with two-thirds giving preference to ages 25-35. In effect, a third of modern respondents, compared to none of the traditional respondents, preferred ages over thirty for a women's first child. The reasons that modern respondents proposed a later age for childbearing were that they related childbearing to careers and finances as well as to their union and material stability:

I=d say probably 25 anyway. After school's done, after she=s gone to work for a while. I think under 21 is inadvisable at best. You don't have any money or experience, any emotional maturity at that age. They don't know what they want, often can $=t$ look after themselves very well even when they don't have kids.[15322, man, age 36, single, no kid, SES low].

[...] I think you have to be a couple before you can bring somebody else into your life. You have to be stable with that relationship before you can add on. [2493, woman, age 34, single, no kid, SES medium].

I think maybe your mid-twenties, early thirties because by then you are hopefully done school and you've gotten a job or career and you're making money and you can support yourself. I suppose you'd be able to support another person. [8043, woman, age 20, single, no kid, SES low].

In contrast, traditional respondents suggested an earlier age for childbearing, in part because they believed that parents should be closer in age to their children:

I think the earlier the better. I think you should be able to grow up with your children. I think the older you get, the more you seem to be leaving them behind. If you have your first child at 40 , that's. I think the children should come along early. [5260, man, age 70, married, 3 kids, SES high].

Some other traditional respondents believed that early childbearing would direct and shape the couple's relationship as a family with children:

Have kids while you're young, then work at making marriage fit around kids. You can cope with them when you're young. Kids need to be looked after and people start to hate kids when you get older. You don't always want to be around them. They're great, but not all the time. [12601, woman, age 57, 4 kids, married, SES low]. 
Amir Erfani and Roderic Beaujot

\section{The ideal number of children}

In response to the question on what you think is the ideal number of children, none of the respondents believed that less than two children was ideal. The ideal numbers that were expressed indicate that even the modern respondents would have above-replacement fertility. The ideal of two children was considerably more common for modern than traditional respondents. Part of the reasons that modern respondents expressed two as the ideal was that they related the ideal family size to the occupational status of parents and the limits of time and finances.

I would say two. I mean just two in that where you have both parents usually working, when you look at it time wise to devote time to two young people is doable. To spread yourself very thin and spread it over four or five is a little harder but it can be done. [16183, woman, age 58, separated, 2 kids, SES medium].

For me two would have been ideal. I think the ideal number is basically what you can afford without hardship. I think children should be treated equally, one shouldn't be involved in everything and the one isn't involved in anything. If you have four children, they have to be equally involved in whatever, and I don't think in this, unless you have a very good annual income, I don't think anybody can afford four children anymore. It was different when I was young, you didn't have that, but in this day an age. [6583, woman, age 49, single, no kid, SES medium].

In contrast, those who gave a range like two-to-four were more likely to be traditional rather than modern respondents. The reasons suggested for the range included those that rejected less than two and more than four children, along with rationales favoring two to four children. They think that an only child is not "desirable" because she or he has no companion of their own age with whom to play and grow up. In addition, the reasons for not having more than four children are often described in terms of time and finances that children take from parents:

No less than two children. Less than two is not desirable because the child lacks the benefits of growing-up with 
siblings. It is selfish for parents to have only one child. [5200, man, age 53, married, 4 kids, SES high].

Two to four is ideal. Well because I think one is a lonely kid. It grows up lonely. It's always by itself everyday. If you have two, you have a playmate and what not. And then if you like more kids, four is a good number. More than that, it's a hell of a lot of work. So two-to-four I think is fine. [4411, woman, separated, 4 kids, SES low].

\section{Summary and Conclusion}

Based on a local qualitative sample from Ontario in 2000, we sought to divide respondents between traditional and modern family orientations using questions regarding the necessity to be married to have children, the acceptability of children in same-sex unions, and the importance for children of having two parents. While there are clearly complex motivations associated with childbearing, the rationales given for childbearing behaviour did not differ extensively across the modern and traditional family orientations. These similarities especially applied to the reasons for having children and the costs and values of children. Nonetheless, persons with modern orientations are more likely to give individual related reasons for having children, and to see the value of children in terms of personal needs and desires. The largest difference relates to the ideal timing of childbearing, as persons with modern orientations are more likely to prefer childbearing in the late 20 s or early 30 s.

The similarity in the rationales associated with childbearing might be interpreted as a common culture of childbearing (Watkins, 2000). This culture, as expressed in London, Ontario, and the surrounding area, includes various legitimate bases not to have children, especially if there is lack of economic security and relationship security. In effect, not wanting to have children is a legitimate reason not to have children. Yet, most want to have children, and two children is the most common ideal. The justification for having children includes individual-related reasons and psychological values like love, joy, happiness and the satisfaction of being with children. There are also family-related reasons and socio-cultural values, like completing a family, continuing the society and having support in old age. Persons with more modern family orientations are more likely to propose individual-level reasons for having children, while those who are more traditional are more likely to suggest family-level reasons, but the differences are not large. 
Amir Erfani and Roderic Beaujot

There are more differences in the ideal number of children, where persons with traditional orientations are more likely to suggest the range of "two-to-four" while those with modern and intermediate orientations are more likely to propose that two children is the ideal. The largest differences occur with regard to views on the best timing for having a first child, with ages over thirty being more common for persons with modern orientations, and persons with traditional orientations are more likely to say that it is circumstances other than age which are the most relevant. Another important difference is that persons with traditional orientations are more likely to say that there is no real cost to having children.

For two-thirds of respondents, children represent important costs, including economic, time, and psychological costs. Nonetheless, all but two respondents proposed that the advantages outweighed the disadvantages. While respondents offer several legitimate reasons not to have children, especially the lack of economic and relationship security, along with the desire not to have children, the majority view implies a culture that supports childbearing, and "two", or sometimes "two-to-four" are seen as the ideal number of children.

In discussing the implications of these results, it is important to note that the persons with traditional orientations are more likely to be older, especially men, while those who are single or cohabiting are most likely to have a more modern orientation. It is also useful to note that, on most considerations, the persons with intermediate views are closer to those with modern orientations. That is, the future of childbearing largely depends on persons with modern views. These respondents largely have positive views on the value of children, and they see two children as ideal, but they want to delay childbearing. Traditional respondents see advantages to early timing in terms of benefits for children and for establishing stable marital unions with children, but modern respondents want to establish their work and life arrangements before having children. This delay will reduce the numbers who become parents, and it will reduce the family sizes of those who have children. For instance, according to the 2001 General Social Survey, women aged 45-54 who had their first child at age 30-34 had an average of 1.8 children compared to 2.3 for those who had their first child at 2024 (Beaujot, 2005: 22).

In terms of the reasons for having children, and the advantages of having children, the modern respondents are more likely to provide rationales that relate to individual fulfillment, or personal interests and needs, rather than sociocultural benefits like the continuance of the family or society. When the time comes, the individual fulfillment may be obtained in other avenues rather than through having children. 
Familial Orientations and the Rationales

for Childbearing Behaviour

Finally, persons with modern orientations toward family are much more accepting of family diversity, which can also undermine childbearing. Given the importance attached to relationship security before having children, some of the respondents who express positive views on the value of children, and offer rationales that are favourable to childbearing, may find themselves, when the time comes, in circumstances where they decide against having children. While the rationales offered by respondents indicate a culture that is supportive of childbearing, and individuals with more modern orientations have views similar to those with traditional orientations on ideal family size and on the value and cost of children, they will probably have fewer children given their more individualistic orientation to childbearing and the conviction that later childbearing is better.

\section{End Notes:}

1. An earlier version of this paper was presented at the annual meeting of the Canadian Population Society, June 2004, University of Manitoba, Winnipeg, Session on Families and childbearing in Canada

\section{References:}

Allan, Graham, Sheila Hawker, and Graham Crow. 2001. "Family diversity and change in Britain and Western Europe," Journal of Family Issues 22: 819-837.

Beaujot, Roderic. 2005. "The net effects of delayed reproduction". In Health Canada, "Changing fertility patterns: Trends and implications." Health Policy Research Bulletin, Issue 10: 21-23.

Folbre, Nancy. 2000." Sleeping beauty awake: Feminism and fertility decline in the twentieth century". Paper presented at meetings of the Population Association of America, Los Angles, 23-25 March 2000.

Giddens, Anthony. 1991. Modernity and self-identity: Self and society in the late modern age. Standford: Stanford University Press.

Giddens, Anthony. 1992. The transformation of intimacy: Sexuality, love and eroticism in modern societies. Stanford: Stanford University Press. 
Amir Erfani and Roderic Beaujot

Hall, David R. 2003." The pure relationship and below replacement fertility," Canadian Studies in Population, 30 (1): 51-69.

Kettle, John. 1980. The big generation. Toronto: McClelland and Stewart.

Lapierre-Adamcyk, Evelyne and Marie-Hélène Lussier. 2003. De la forte fécondité à la fécondité désiréé. Pp. 66-109 in V. Piché and Céline Le Bourdais (editors), La démographie québécoise : enjeux du XXIe siècle. Montréal : Presses de l'Université de Montréal.

Lesthaeghe, Ron, and Dominique Meekers. 1986. "Value changes and the dimensions of familialism in the European community." European Journal of Population 2(3/4): 225-68.

Lesthaeghe, Ron, and Johan Surkyn. 1988."Cultural dynamics and economic theories of fertility change." Population and Development Review 14 (1): $1-45$.

Lesthaeghe, Ron. 1995. "The second demographic transition in Western countries: An interpretation," in K. O. Mason and A. M. Jensen (eds.) Gender and Family Change in Industrialized Countries. New York: Oxford University Press. Pp. 17-62.

Lesthaeghe, R. and G. Moors. 2000. "Life course transitions and value orientations: selection and adaptation", Interuniversity Papers in Demography (IPD) Working Paper 2000-7, Interface Demography, VU Brussels.

Moors, Guy.1996. "The valued child: The effect of values on the transition to motherhood," Stockholm Research Reports in Demography No. 107, University of Stockholm.

Roussel, Louis. 1989. La famille incertaine. Paris: Editions Odile Jacob.

Surkyn, J. and R. Lesthaeghe (2002): "Values orientations and the Second Demographic Transition (SDT) in northern, western and southern Europe - An update", IPD Working Paper, Interface Demography, VU Brussels.

Thornton, Arland. 2001. "The development paradigm, reading history sideways, and family change". Demography 38: 449-465.

Van de Kaa, Dirk. J. 1987.” Europe's second demographic transition,” Population Bulletin 42: 1-59. 
Familial Orientations and the Rationales for Childbearing Behaviour

Van de Kaa, Dirk. J. 2001. "Postmodern fertility preferences: From changing value orientation to new behavior", in Rodolfo A. Bulatao and John B. Casterline (eds.) Global Fertility Transition. A supplement to Population Development Review 27: 290-331.

Watkins, Susan Cotts. 2000. Local and foreign models of reproduction in Nyanza Province, Kenya. Population and Development Review 26 (4): 725-760. 